\title{
Biological Characterization of a $\beta$-Galactosidase Expressing Clone of Trypanosoma cruzi CL Strain
}

\author{
Ana Le-Senne, Susana Muelas-Serrano, Carlos Fernández-Portillo, José Antonio Escario, \\ Alicia Gómez-Barrio ${ }^{+}$
}

Departamento de Parasitología, Facultad de Farmacia, Universidad Complutense, Ciudad Universitaria s/n, 28040 Madrid, España

Clone CL B5 of Trypanosoma cruzi is a $\beta$-galactosidase expressing organism that was genetically transfected to be used for in vitro pharmacological screening. Biological parameters were determined, evaluating growth kinetics of epimastigotes, metacyclogenesis, infectivity to mammalian cell lines, parasitemia kinetics in mice and sensibility to nifurtimox and benznidazole. Differences in relation to other strains and CL parental strain were found, the most important being the incapability to produce death to mice in spite of the high inoculum used. However, it possesses the required features to be used for in vitro drug screening. Data obtained demonstrate that heterogeneity of T. cruzi appears even among clones of the same strain, and that these differences found do not prevent the use of clone CL B5 for the purpose that was engineered.

Key words: Trypanosoma cruzi - clone CL B5 - biological characterization

Trypanosoma cruzi is the causative agent of Chagas disease, and it is estimated that this disease affects 16-18 million persons in South America, causing around 50,000 deaths yearly (Kirchhoff 1994). In spite of the great effort accomplished since the discovery of Chagas (1909), no definitive treatment has been achieved against this disease. There is a large number of publications concerning the research of new products with trypanocidal activity (Stoppani 1999) and the study of pharmacological targets of this parasite (Werbovetz 2000). However, the only two drugs available for clinical use are nifurtimox and benznidazole, being the production of the first one discontinued at the moment (Croft et al. 1997). It is widely accepted that both products are effective in the acute phase of the infection, but treatment of chronic Chagas disease remains controversial, due to the fact that patients treated with these compounds are not parasitologically cured, as demonstrated by competitive PCR tests (Braga et al. 2000). Moreover, both nifurtimox and benznidazole produce severe side effects, which often lead to an interruption of treatment (Castro \& Díaz de Torranzo 1988). In this regard, it remains an open field of investigation the search of new drugs without the undesirable side effects of the reference compounds and with the capacity to promote a true parasitological cure.

Selection of new trypanocidal compounds by classical methods implies the tedious work of microscopic counting (Martínez-Díaz et al. 2000, Muelas-Serrano et al. 2000, 2001). Development of new techniques to avoid the labour-intensive microscopic counting are always welcome. Buckner et al. (1996) reported an efficient method

${ }^{+}$Corresponding author. Fax: +34-1-394.1815. E-mail: agbarrio@farm.ucm.es

Received 3 January 2002

Accepted 8 August 2002 for the quantification of T. cruzi parasites in drug screening assays. T. cruzi strain CL parasites were genetically engineered to express the Escherichia coli $\beta$-galactosidase gene, lacZ. This enzyme is able to catalyse a colorimetric reaction. The amount of $\beta$-galactosidase activity is directly proportional to the number of transfected parasites (clone CL B5). The efficiency of the assay facilitates the screening of a larger number of candidate compounds against T. cruzi (Buckner et al. 1996).

Heterogeneity in relation to biological properties is a patent feature of T. cruzi. Parasite isolates express differences in growth rates, infectivity, tissue tropism, antigenic composition, virulence and mortality in animal models, susceptibility to immune sera and chemotherapeutic drugs (Andrade et al. 1975, 1985, Brener et al. 1976a, de Castro \& Meirelles 1986, Melo \& Brener 1978, Neal \& van Bueren 1988, Rovai et al. 1990). To our knowledge an intensive characterization of the clone CL B5 of T. cruzi, concerning biological parameters, has not been done. For this reason the purpose of this work is the description of features of this clone regarding growth kinetics of epimastigotes, metacyclogenesis in Grace medium, infectivity in mammalian cells grown in vitro, susceptibility to reference drugs and kinetics of mice infection. A study of such nature is important for a better understanding of this clone's behaviour, since it is being used for drug screening by research some groups worldwide (Buckner et al. 2001) and biological differences between parental strain and clones have been previously reported (Zingales et al. 1997a).

\section{MATERIALS AND METHODS}

Parasites - T. cruzi clone CL B5 was kindly provided by Dr F Buckner through Instituto Conmemorativo Gorgas (Panama). (NMRI) mice were inoculated intra-peritoneally with the clone. After exsanguination, blood was cultured in glass tubes with $5 \mathrm{ml}$ of LIT medium supplemented with $10 \%$ heat-inactivated foetal calf serum (FCS). Two subcultures were performed in this medium before biological features were studied. 
Growth curves - To determine growth kinetics, $5 \mathrm{ml}$ of epimastigotes suspension in LIT medium $+10 \% \mathrm{FCS}$ at two different concentrations, $10^{5}$ and $5 \times 10^{5} \mathrm{par} / \mathrm{ml}$, were maintained at $28^{\circ} \mathrm{C}$. The concentration of the parasites was counted in a haemocytometer chamber up to the 23rd day in culture. This assay was performed four times and average and standard deviation values were calculated.

Metacyclogenesis - Metacyclogenesis was achieved by transformation of epimastigotes in modified Grace medium (Osuna-Carrillo et al. 1979) supplemented with 10\% FCS and haemin (Arévalo et al. 1985). Stationary phase axenic cultures of epimastigotes were collected by centrifugation and washed in fresh Grace medium. Eight million epimastigotes $/ \mathrm{ml}$ were seeded in $10 \mathrm{ml}$ of metacyclogenesis medium. Up to 23 days culture density was determined in haemocytometer and the percentage of different morphological types was calculated after microscopic counting of Giemsa stained smears.

Infectivity to cultured mammalian cells - A non-phagocytic cell line (Vero fibroblasts) and a phagocytic one (J774 macrophages) were used to study infectivity. Vero fibroblasts were cultured in Minimum Essential Medium $+20 \%$ FCS and J774 macrophages in RPMI Medium + $20 \%$ FCS. In both cases 50,000 cells/well were seeded on sterile round coverslips placed on 24-well plates. Then trypomastigotes were added in different quantities: (A) 50,000/well, (B) 100,000/well, (C) 250,000/well and (D) $500,000 /$ well. Culture medium was added to a final volume of $2 \mathrm{ml}$. Metacyclic trypomastigotes were allowed to invade cells for $24 \mathrm{~h}$, at $37^{\circ} \mathrm{C}$ and $5 \% \mathrm{CO}_{2}$. Coverslips were fixed and stained with May Grünwald Giemsa after 24, 48, 72,96 and $168 \mathrm{~h}$ and percentage of infected cells, number of amastigotes/100 cells and number of amastigotes/infected cell were calculated by microscopic counting. Each test was run in triplicates (Mendez et al. 1997).

In vivo infectivity - Infected blood was obtained from anaesthetised donor-mice by intra-cardiac puncture and diluted with non-infected blood yielding the desired number of bloodstream trypomastigotes. Three groups of 10 NMRI female mice were infected by intra-peritoneal injection of respectively $10^{3}, 10^{4}$ and $10^{5}$ bloodstream trypomastigotes. The level of parasitemia was checked by counting in a Neubauer chamber the number of parasites in $5 \mu \mathrm{l}$ of blood drawn from the tail of mice and diluted 1:10 in ammonium chloride (Barr et al. 1995).

Susceptibility to chemotherapeutic agents - Parasite sensibility to nifurtimox or benznidazole was assayed using epimastigote cultures as previously described (Muelas-Serrano et al. 2000). Three drug concentrations were used: 100, 10 and $1 \mu \mathrm{g} / \mathrm{ml}$. Assays were performed in triplicate. Percentage of anti-epimastigote activity was calculated as follows:

$\% \mathrm{EA}=100 \times[1-($ no. epimastigotes $/ \mathrm{ml}$ treated $/$ no. epimastigotes $/ \mathrm{ml}$ control $]$

Sensibility of intracellular amastigotes to reference drugs was also tested. Assays were carried out as described in Muelas-Serrano et al. (2001). Due to the high infectivity of this clone, a mammalian cell-parasite ratio of $1: 2$ was used. Anti-amastigote activity was calculated as follows:
$\% \mathrm{AA}=100 \times\left[1-\left(\right.\right.$ no. amastigotes $/ 100 \mathrm{M} \emptyset_{\text {treated }} /$ no. amastigotes/100 MØ control $)]$

\section{RESULTS}

Epimastigotes growth curve is shown in Fig. 1. Using both inocula $\left(10^{5}\right.$ and $5 \times 10^{5}$ parasites $\left./ \mathrm{ml}\right)$ a growth peak over $14 \times 10^{6}$ epimastigotes/ml was reached, but this peak occurred 3 days later in experience with the lowest inoculum. Stationary phase started immediately thereafter and culture density lowered to around $2 \times 10^{6}$ epimastigotes $/ \mathrm{ml}$ for another 10 days. Transformation to metacyclic forms is represented in Fig. 2. Percentage of epimastigotes decreased up to a limit around 50\%, at the same time percentage of trypomastigotes increased reaching a maximum around day 16 of $39 \%$, and that of intermediary forms remained constant and around 5\%.

Tables I and II show assays of infectivity to Vero fibroblasts and J774 macrophages, respectively. For Vero cells, the number of amastigotes/infected cell increases until $96 \mathrm{~h}$ of incubation, thereafter new trypomastigotes are liberated and infect other host cells, thus increasing significantly the number of amastigotes/100 cells after 168 $\mathrm{h}$ of incubation. J774 macrophages are dramatically infected, even with infection ratio of 1:1. When infection ratio is higher than $1: 2$, cells are so intensively infected that they break after only $24 \mathrm{~h}$ of culture and free amastigotes can be observed. When using an infection ratio of 1:10, J774 macrophages are simply destroyed, thus

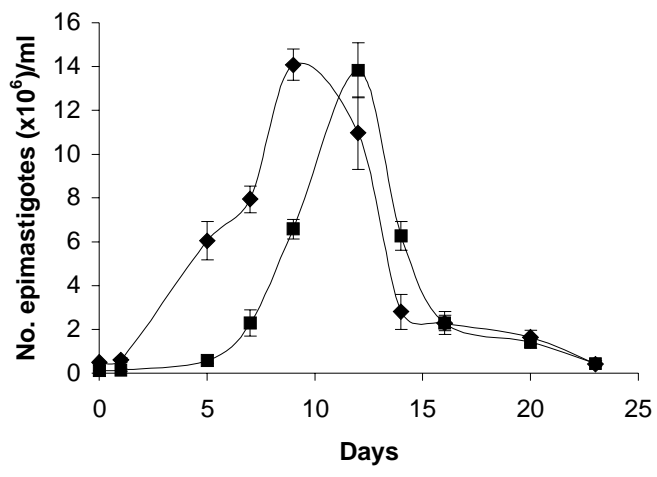

Fig. 1: in vitro growth curves of epimastigotes of clone CL B5 in LIT medium in different concentrations $(\diamond) 5 \times 10^{5}$ epimastigotes/ $\mathrm{ml},(\mathbf{\square}) 10^{5}$ epimastigotes $/ \mathrm{ml}$

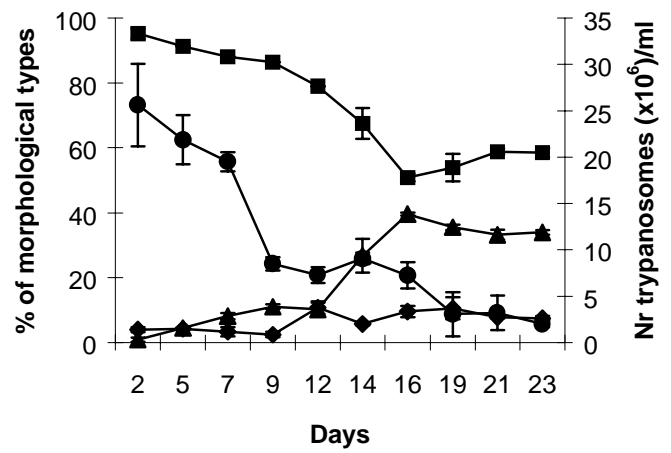

Fig. 2: kinetics of morphological transformation of clone CL B5 in modified Grace medium; $(\mathbf{\square})$ percentage of epimastigotes; $(\boldsymbol{\Delta})$ percentage of trypomastigotes; ( $)$ percentage of intermediary forms; (•) number of trypanosomes $/ \mathrm{ml}$ 
counting is almost impossible. In the case of $\mathrm{J} 774$ cells, reinfection occurs earlier than for Vero cells, $96 \mathrm{~h}$ after first cell-parasite contact, as can be deduced by the important decrease of percentage of non-infected cells and increase in number of amastigotes/100 macrophages.

Parasitemia kinetics in NMRI mice is plotted in Fig. 3. As it can be observed infectivity peaks occur between days 12 and 15 . No animal died during the experience and parasitemia was kept relatively low, reaching a maximum of $10^{5}$ trypomastigotes $/ \mathrm{ml}$ of blood for the highest inoculum injected.

Susceptibility to reference drugs is shown in Table III. Both compounds reduce number of parasites at 100 and $10 \mu \mathrm{g} / \mathrm{ml}$ significantly; activity at $1 \mu \mathrm{g} / \mathrm{ml}$ is unimportant.

TABLE I

Infection of vero fibroblast with metacyclic trypomastigotes of clone CL B5

\begin{tabular}{|c|c|c|c|c|c|c|c|}
\hline \multirow[t]{2}{*}{ Ratio } & \multirow{2}{*}{$\begin{array}{c}\text { Culture } \\
\text { hours }\end{array}$} & \multicolumn{4}{|c|}{$\%$ vero cells infected } & \multirow{2}{*}{$\begin{array}{c}\text { No. ama/ } \\
\text { inf. cell }\end{array}$} & \multirow{2}{*}{$\begin{array}{c}\text { No. ama/ } \\
100 \text { cells }\end{array}$} \\
\hline & & 1-5 ama/cell & 6-10 ama/cell & 11-20 ama/cell & $>20 \mathrm{ama} /$ cell & & \\
\hline \multirow[t]{5}{*}{$1: 1$} & 24 & $9.3 \pm 0.4$ & $0.3 \pm 0.4$ & 0 & 0 & $1.4 \pm 0.1$ & $15.8 \pm 3.2$ \\
\hline & 48 & $10 \pm 1.4$ & $1.3 \pm 1.1$ & $0.3 \pm 0.4$ & 0 & $2.4 \pm 0.5$ & $29.3 \pm 1.1$ \\
\hline & 72 & $3.5 \pm 0.7$ & $3.3 \pm 2.5$ & $1.5 \pm 0.7$ & $0.5 \pm 0.7$ & $7.1 \pm 0.9$ & $61.5 \pm 5$ \\
\hline & 96 & 0 & $0.3 \pm 0.7$ & $0.5 \pm 0.7$ & 1 & $29.2 \pm 1.1$ & $58 \pm 18.4$ \\
\hline & 168 & $12.3 \pm 2.5$ & $3 \pm 0.7$ & $4.3 \pm 1.8$ & $5.5 \pm 0.7$ & $12 \pm 3.3$ & $298.3 \pm 73.2$ \\
\hline \multirow[t]{5}{*}{$1: 2$} & 24 & $15.5 \pm 3.5$ & 0 & 0 & 0 & 1.3 & $20.5 \pm 5$ \\
\hline & 48 & $15.3 \pm 0.4$ & $1 \pm 0.7$ & 0 & 0 & $2.1 \pm 0.2$ & $33.5 \pm 2.8$ \\
\hline & 72 & $6.3 \pm 4$ & $1.5 \pm 0.7$ & $1.3 \pm 1.8$ & $1 \pm 0.7$ & $7.9 \pm 5.6$ & $76.5 \pm 50.2$ \\
\hline & 96 & 0 & $1 \pm 1.4$ & 1 & $2.5 \pm 0.7$ & $24.1 \pm 5$ & $106.5 \pm 5.7$ \\
\hline & 168 & $10.5 \pm 7.1$ & $4.3 \pm 1.8$ & $5.5 \pm 1.4$ & $7.3 \pm 0.4$ & $16.1 \pm 2.4$ & $445.8 \pm 23$ \\
\hline \multirow[t]{5}{*}{$1: 5$} & 24 & $27.3 \pm 0.4$ & $1.3 \pm 0.4$ & 0 & 0 & 1.9 & $54.8 \pm 1.1$ \\
\hline & 48 & $25 \pm 1.4$ & $1.5 \pm 0.7$ & $0.5 \pm 0.7$ & 0 & $2.3 \pm 0.2$ & $62.8 \pm 8.1$ \\
\hline & 72 & $8.3 \pm 10.3$ & $3.5 \pm 2.8$ & 2.5 & $0.8 \pm 1.1$ & $10.8 \pm 8.7$ & $109 \pm 0.7$ \\
\hline & 96 & $1.3 \pm 0.4$ & $1.3 \pm 0.4$ & $1 \pm 0.8$ & $3.5 \pm 1.4$ & $24.1 \pm 3$ & $172.3 \pm 72.5$ \\
\hline & 168 & $12 \pm 3.5$ & $4.3 \pm 1.8$ & $7.5 \pm 3.5$ & $10.8 \pm 1.1$ & $16.2 \pm 3.6$ & $564 \pm 168.3$ \\
\hline \multirow[t]{5}{*}{$1: 10$} & 24 & $29.5 \pm 1.8$ & 0.5 & 0 & 0 & $1.8 \pm 0.1$ & $56.3 \pm 2.5$ \\
\hline & 48 & $29.3 \pm 0.4$ & $2.8 \pm 1.1$ & $0.8 \pm 0.4$ & 0 & $2.5 \pm 0.3$ & $74.8 \pm 3.4$ \\
\hline & 72 & $5.5 \pm 3.5$ & $3 \pm 0.7$ & $3.8 \pm 0.4$ & $3.3 \pm 1.8$ & $14.4 \pm 5.4$ & $217 \pm 53$ \\
\hline & 96 & 0 & $0.3 \pm 0.4$ & $3.5 \pm 0.7$ & $3.8 \pm 1.1$ & $27.1 \pm 4.3$ & $210 \pm 93.3$ \\
\hline & 168 & $29.5 \pm 10.6$ & 5.5 & 11 & $9 \pm 5$ & $10.5 \pm 2.8$ & $587.8 \pm 122.9$ \\
\hline
\end{tabular}

ama: intracellular amastigotes

TABLE II

Infection of J774 macrophages with metacyclic trypomastigotes of clone CL B5

\begin{tabular}{|c|c|c|c|c|c|c|c|}
\hline \multirow[t]{2}{*}{ Ratio } & \multirow{2}{*}{$\begin{array}{l}\text { Culture } \\
\text { hours }\end{array}$} & \multicolumn{4}{|c|}{$\% \mathrm{M} \varnothing$ cells infected } & \multirow{2}{*}{$\begin{array}{l}\text { No. amas/ } \\
\text { inf. cell }\end{array}$} & \multirow{2}{*}{$\begin{array}{c}\text { No. amas/ } \\
100 \text { cells }\end{array}$} \\
\hline & & 1-5 amas/ cell & 6-10 amas /cell & 11-20 amas/cell & $>20$ amas/ cell & & \\
\hline \multirow[t]{5}{*}{$1: 1$} & 24 & $35.2 \pm 1.5$ & $4.7 \pm 0.9$ & $0.9 \pm 0.5$ & 0 & $3.2 \pm 0.2$ & $130.1 \pm 15.2$ \\
\hline & 48 & $36.3 \pm 2.5$ & $7.5 \pm 4.2$ & $4.3 \pm 0.4$ & 0.5 & $4.5 \pm 0.3$ & $216.3 \pm 23.7$ \\
\hline & 72 & $33.5 \pm 2.1$ & $12 \pm 1.4$ & $3.5 \pm 1.4$ & $2.5 \pm 0.7$ & $6.2 \pm 1.2$ & $294.8 \pm 42.1$ \\
\hline & 96 & $43.3 \pm 4.6$ & $25.3 \pm 3.2$ & $13 \pm 3.5$ & $6 \pm 2.1$ & $7.9 \pm 0.4$ & $690.8 \pm 1.8$ \\
\hline & 168 & $25.5 \pm 7.1$ & $35.3 \pm 3.9$ & $25.8 \pm 3.2$ & $11.8 \pm 6.7$ & $11.2 \pm 2.1$ & $1099.8 \pm 194.1$ \\
\hline \multirow[t]{5}{*}{$1: 2$} & 24 & $35.8 \pm 3.6$ & $13.4 \pm 2.5$ & $4.8 \pm 1.7$ & $0.4 \pm 0.5$ & $5 \pm 0.9$ & $264.6 \pm 40.4$ \\
\hline & 48 & $32.8 \pm 3.2$ & $13.3 \pm 0.4$ & $10 \pm 2.8$ & 2 & $6.6 \pm 0.2$ & $384.5 \pm 5.7$ \\
\hline & 72 & $35.3 \pm 1.1$ & $17.3 \pm 4.6$ & $6 \pm 0.7$ & $4.3 \pm 3.2$ & $7.2 \pm 1.5$ & $446.8 \pm 81$ \\
\hline & 96 & $43.8 \pm 1.8$ & $23.3 \pm 1.1$ & $11 \pm 0.7$ & 12.5 & $10.1 \pm 0.2$ & $910.8 \pm 13.8$ \\
\hline & 168 & $14.5 \pm 5.7$ & $27.5 \pm 2.1$ & $31.6 \pm 1.4$ & $25 \pm 2.1$ & $15.2 \pm 0.4$ & $1500.5 \pm 33.2$ \\
\hline \multirow[t]{5}{*}{$1: 5$} & 24 & $37.6 \pm 5.1$ & $18.5 \pm 1.6$ & $15.5 \pm 3.7$ & $4.4 \pm 0.9$ & $7.7 \pm 0.8$ & $586.4 \pm 54.3$ \\
\hline & 48 & $40.8 \pm 3.9$ & $10 \pm 2.1$ & $7 \pm 0.7$ & $2.8 \pm 1.1$ & $5.8 \pm 0.4$ & $351 \pm 12.7$ \\
\hline & 72 & $43.5 \pm 2.8$ & $12.3 \pm 1.8$ & $9.3 \pm 2.5$ & $3 \pm 0.7$ & $6.2 \pm 0.5$ & $421.8 \pm 24.4$ \\
\hline & 96 & $36 \pm 8.5$ & $25.5 \pm 2.8$ & $16.8 \pm 3.2$ & $13 \pm 2.8$ & $11.2 \pm 1.1$ & $1024 \pm 97.6$ \\
\hline & 168 & $6.3 \pm 2.5$ & $14 \pm 7.8$ & $30.5 \pm 7.8$ & $46.5 \pm 21.2$ & $25.9 \pm 8.1$ & $2534.5 \pm 880.4$ \\
\hline $1: 10 \mathrm{a}, \mathrm{b}$ & 24 & $24.5 \pm 0.7$ & $0.8 \pm 0.4$ & 0 & 0 & 1.1 & $45.5 \pm 2.8$ \\
\hline$a, b$ & 48 & $37.9 \pm 0.5$ & $16.6 \pm 5.8$ & $10.4 \pm 5.9$ & $2.8 \pm 4$ & $6.5 \pm 1.7$ & $453.4 \pm 216.9$ \\
\hline $\mathrm{a}, \mathrm{b}$ & 72 & $37.1 \pm 2$ & $20.1 \pm 5.8$ & $15 \pm 0.7$ & $16.7 \pm 3.8$ & $11.6 \pm 0.5$ & $1038.2 \pm 129.6$ \\
\hline$a, b$ & 96 & $45.9 \pm 1.5$ & $16.8 \pm 10.4$ & $16.1 \pm 6.6$ & $6.8 \pm 4.7$ & 8.9 & $763.5 \pm 95.5$ \\
\hline$a, b$ & 168 & $48 \pm 12.7$ & $12.3 \pm 3.2$ & $11.8 \pm 6$ & $16.8 \pm 7.4$ & $14.8 \pm 3.5$ & $1320 \pm 364.2$ \\
\hline
\end{tabular}

ama: intracellular amastigotes; a: there are some free amastigotes and broken macrophages; b: destroyed cell culture. A low number of cells with cytoplasm 


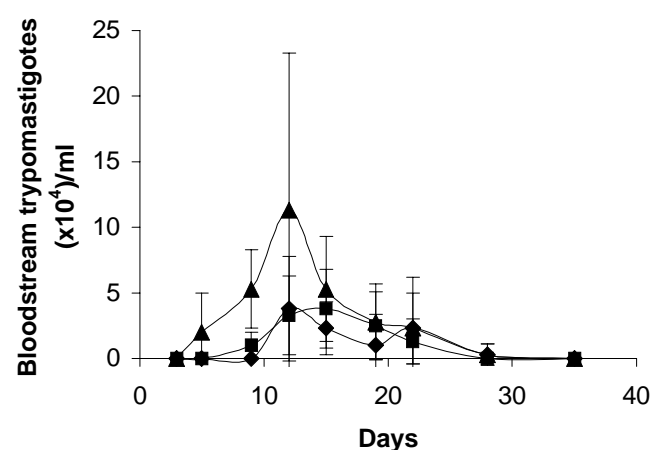

Fig. 3: parasitemia kinetics curve, with different inocula of bloodstream trypomastigotes $(\boldsymbol{\Delta}) 10^{5}$ parasites; ( $\left.\mathbf{\square}\right) 10^{4}$ parasites; $(\bullet)$ $10^{3}$ parasites

TABLE III

Susceptibility to reference drugs of epimastigotes and intracellular amastigotes

\begin{tabular}{lccc}
\hline Drug $(\mu \mathrm{g} / \mathrm{ml})$ & 100 & 10 & 1 \\
\hline \multicolumn{4}{c}{$\%$ inhibition of epimastigotes } \\
\hline Nifurtimox & 100 & $86.5 \pm 5.0$ & $23.0 \pm 2.4$ \\
Benznidazole & 100 & $9.6 \pm 2.8$ & 0 \\
\hline \multicolumn{4}{c}{$\%$ inhibition of intracellular amastigotes } \\
\hline Nifurtimox & $90.1 \pm 2.2$ & $84.64 \pm 3.2$ & $41.0 \pm 1.4$ \\
Benznidazole & $92.8 \pm 2.6$ & $58.31 \pm 3.8$ & $16.5 \pm 9.1$ \\
\hline
\end{tabular}

\section{DISCUSSION}

CL strain presents important characteristics of T. cruzi: such as isolation from a strictly domiciliary vector, Triatoma infestans, differentiation in liquid medium, infection to cell monolayers with has preferential parasitism of heart and muscle cells. It presents defined parasitemia curves and mortality in mice, and shows a clear acute phase in accidentally infected humans being highly susceptible to drugs used clinically in Chagas disease (Zingales et al. 1997a). For this reason clone CL Brener was selected for T. cruzi genome project (Zingales et al. $1997 \mathrm{c}$ ) and on the same line, a $\beta$-galactosidase clone (CL B5) was engineered for drug screening (Buckner et al. 1996). This latter clone was described as very stable and as having in vitro growth rates as epimastigotes and as mammalian forms very similar to those of non-transfected parasites (Buckner et al. 1996), but no further information was given about other biological parameters. From our point of view, an extensive characterization of this clone was required, since it is being frequently used for drug screening (Buckner et al. 2001).

The growth of CL B5 epimastigotes in LIT medium shows some differences in relation to Bolivia and GM strains (Martínez Díaz et al. 2001) in the same experimental conditions. Although the peak of parasite concentration occurs at similar time for the three populations, for CL B5 it is slightly lower and the density at stationary phase is about $2 \times 10^{6}$ epimastigotes $/ \mathrm{ml}$, while with both strains the value of $20 \times 10^{6}$ epimastigotes $/ \mathrm{ml}$ is maintained. Differentiation indices to metacyclic forms in Grace's medium were up to $40 \%$. Differentiation is slow, starting after 9 days of incubation at $28^{\circ} \mathrm{C}$ and reaching a peak at day 16. Percentage of metacyclic forms is similar to that of the parental strain but is reached after 16 days instead of 7-10 days (Zingales et al. 1997a).

As other CL clones, amastigote to trypomastigote differentiation takes place at $37^{\circ} \mathrm{C}$ (Zingales et al. 1997a), contrasting to the $\mathrm{CL}$ parental strain requirement of $33^{\circ} \mathrm{C}$ (Brener et al. 1976b). Our data indicate that clone CL B5 is able to penetrate phagocytic and non-phagocytic cells efficiently when compared to other strains (Zingales et al. 1997a, Martínez-Díaz et al. 2001). On the other hand, if phagocytic cells are to be used as host mammalian cells in drug screening assays, a cell-parasite ratio of 1:2, instead of 1:10 (Muelas et al. 2001) is recommended, since at higher ratios host cell destruction is observed.

In vitro assays with reference drugs, informs us that both epimastigotes and intra-cellular amastigotes are not resistant to nifurtimox and benznidazole, as occurs in the case of CL strain (Zingales et al. 1997b).

The main biological difference observed in clone CL B5 in relation to CL strain is its lower infectivity to mice. While parental strain causes high levels of parasitemia and $100 \%$ of mortality in Balb/C mice following the i.p. inoculation of $5 \times 10^{3}$ bloodstream forms (Zingales et al. 1997b), clone CL B5 infection produces no deaths in NMRI mice, even following an infection with $10^{5}$ bloodstream trypomastigotes.

In spite of the low in vivo infectivity of this clone, this extensive biological characterization demonstrated that clone CL B5 has the important features required for in vitro drug screening, since it grows adequately in liquid medium as epimastigotes, it differentiates and infects different cell lines intensively and it is susceptible to reference drugs. After all, this clone has been engineered for in vitro assays, so mice infectivity is not a necessary characteristic.

\section{REFERENCES}

Andrade SG, Figeira RM, Carvalho ML, Gorini DF 1975. Influência da cepa do Trypanosoma cruzi na resposta à terapêutica experimental pelo Bay 2502. Rev Inst Med Trop São Paulo 17: 330-339.

Andrade SG, Magalhães JB, Pontes AL 1985. Evaluation of chemotherapy with benznidazole and nifurtimox in mice infected with Trypanosoma cruzi strains of different types. Bull WHO 63: 721-726.

Arévalo J, Panebra A, Santa Cruz C 1985. Relevance of hemin for in vitro differenciation of Trypanosoma cruzi. $J$ Protozool 32: 553-555.

Barr SC, Rose D, Jaynes JM 1995. Activity of lytic peptides against intracellular Trypanosoma cruzi amastigotes in vitro and parasitemia in mice. J Parasitol 81: 974-978.

Braga MS, Lauria-Pires L, Argañaraz ER, Nascimento RJ, Teixeira RL 2000. Persistent infections in chronic Chagas' disease patients treated with anti-Trypanosoma cruzi nitroderivatives. Rev Inst Med Trop São Paulo 42: 157-161.

Brener Z, Costa CA, Chiari E 1976a. Differences in the susceptibility of Trypanosoma cruzi to active chemotherapeutic agents. Rev Inst Med Trop São Paulo 11: 245-249.

Brener Z, Golgher R, Bertelli MS, Texeira JA 1976b. Strain- 
dependent thermosensitivity influencing intracellular differentiation of Trypanosoma cruzi in cell culture. J Protozool 23: 147-150.

Buckner FS, Verlinde CLMJ, La Flamme AC, van Voorhis WC 1996. Efficient technique for screening drugs activity against Trypanosoma cruzi using parasites expressing $\beta$-galactosidase. Antimicrob Agents Chemother 40: 2592-2597.

Buckner FS, Griffin JH, Wilson AJ, van Voorhis WC 2001. Potent anti-Trypanosoma cruzi activities of oxidosqualene cyclase inhibitors. Antimicrob Agents Chemother 45: 12101215.

Castro JA, Díaz de Torranzo EG 1998. Toxic effects of nifurtimox and benznidazole, two drugs used against American tripanosomiasis (Chagas disease). Biomed Environ Sci 1: 19-33.

Croft SL, Urbina JA, Brun R 1997. Chemotherapy of human leishmaniasis and trypanosomiasis. In G Hide, JC Mottram, GH Coombs, PH Holmes (eds), Trypanosomiasis and Leishmaniasis Biology and Control, CAB International, Wallingford, Oxon, p. 245-257.

de Castro SL, Meirelles MN 1986. Effect of drugs on Trypanosoma cruzi and on its interaction with heart muscle cell in vitro. Mem Inst Oswaldo Cruz 82: 209-218.

Kirchhoff LV 1994. American trypanosomiasis (Chagas' disease) and African trypanosomiasis (sleeping sickness). Curr Op Infect Dis 7: 542-546.

Martínez-Díaz RA, Escario JA, Nogal Ruiz JJ, Gómez-Barrio A 2000. Evaluation of drug activity against intracellular forms of Trypanosoma cruzi employing enzyme immunoassay. J Clin Pharm Ther 25: 43-47.

Martínez-Díaz RA, Escario JA, Nogal Ruiz JJ, Gómez-Barrio A 2001. Biological characterization of Trypanosoma cruzi strains. Mem Inst Oswaldo Cruz 96: 53-59.

Melo RC, Brener Z 1978. Tissue tropism of different Trypanosoma cruzi strains. J Parasitol 64: 475-482.

Mendez S, Nell M, Fernández-Pérez FJ, Alunda JM 1999. Sensitivity of Leishmania infantum amastigotes to fluorinated L-ornithine analogues. Med Sci Res 27: 87-89.

Muelas S, Di Maio R, Cerecetto H, Seoane G, Ochoa C, Escario JA, Gómez-Barrio A 2001. New thiadiazine derivatives with activity against Trypanosoma cruzi amastigotes. Folia Parasitol 48: 105-108.

Muelas-Serrano S, Nogal JJ, Gómez-Barrio A 2000. Setting of a colorimetric method to determine the viability of Trypanosoma cruzi epimastigotes. Parasitol Res 86: 999-1002.

Muelas-Serrano S, Perez-Serrano J, Gómez-Barrio A, Ochoa C, Martínez J, Rodriguez-Caabeiro F 2001. In vitro effects of anti-Trypanosoma cruzi compounds on HSP60 levels. Parasitol Res 87: 615-618.

Neal RA, van Bueren J 1988. Comparative studies of drugs susceptibility of five strain of Trypanosoma cruzi in vivo an in vitro. Trans R Soc Trop Med Hyg 82: 709-714.

Osuna-Carrillo A, Jiménez-Ortiz A, Lozano-Maldonado J 1979. Medios de cultivo para la obtención de formas metacíclicas de Trypanosoma cruzi. Rev Ibér Parasitol 39: 129-133.

Rovai LE, Aoki A, Gerez de Burgos NM, Blanco A 1990. Effect of gossypol on trypomastigotes and amastigotes of Trypanosoma cruzi. J Protozool 37: 280-286.

Stoppani AOM 1999. Quimioterapia de la enfermedad de Chagas. Medicina 59: 147-165.

Werbovetz KA 2000. Target-based drug discovery for malaria, leishmaniasis, and trypanosomiasis. Curr Med Chem 7: 835860.

Zingales B, Pereira MES, Almeida KA, Ulmezawa ES, Nehme NS, Oliveira RP, Macedo A, Souto RP 1997a. Biological parameters and molecular markers of clone CL Brener-The reference organism of the Trypanosoma cruzi genome project. Mem Inst Oswaldo Cruz 92: 811-814.

Zingales B, Pereira MES, Oliveira RP, Almeida KA, Ulmezawa ES, Souto RP, Vargas N, Cano MI, Franco da Silveira J, Nehme NS, Morel CM, Brener Z, Macedo A 1997b. Trypanosoma cruzi genome project: biological characteristics and molecular typing of clone CL Brener. Acta Trop 68: 159173.

Zingales B, Rondinelli E, Degrave W, De Silveira JF, Levin M, Le Paslier D, Modabber F, Dobrokhotov B, Swindle J, Kelly JM, Aslund L, Hoheisel JD, Ruiz AM, Cazzulo JJ, Petterson U, Frasch AC (The Trypanosoma cruzi Genome Consortium) 1997c. The Trypanosoma cruzi genome initiative. Parasitol Today 13: 16-22. 